\title{
A Comparative Study on the R and D Capital Stock in China
}

\author{
Lijing Yu \\ Yantai Nanshan University \\ Yantai, China 265700
}

\author{
Li Yang \\ Yantai Nanshan University \\ Yantai, China 265700
}

\begin{abstract}
R and D capital stock plays an important role in the economic growth accounting analysis. By using the perpetual inventory method of capital stock model, this paper estimated the $R$ and $D$ capital stock of 30 inland provinces and autonomous regions in our country from 2003 to 2013, and made comparative analysis on various regions. The results show that the $R$ and $D$ capital stock of our country is increasing during the period of this research. Regional development is unbalanced, rich-poor polarization is serious and the concentration is high; furthernore, the distribution presents ladder-like characteristic of chinese economic regions, diminishing from the eastern region to the northwest, the central region and the western region. From the growth rate, we can find the eastern region is still far ahead but the development of the northeast region is slow, while the central region is catching up with the eastern region and the western region is difficult to change its situation in the near future.
\end{abstract}

Keywords-R and $D$ inputs; capital stock; perpetual inventory method; distribution characteristics

\section{INTRODUCTION}

With the development of society, technological innovation has become the endogenous driving force of economic growth. R\&D activities and technological innovation is closely related, is the core of the technological innovation, R\&D investment can effectively promote technological innovation ${ }^{[1]}$. Taking into account the R\&D into memory and delay tired, the amount of $R \& D$ invested by $R \& D$ is more scientific. At the same time, Li Xiaosheng and $\mathrm{Li}$ Shumei $\mathrm{i}^{[2-3]}$, etc. also pointed out that the R\&D capital stock is an important role on the empirical analysis of the economic growth and economic growth. So far, the domestic and foreign research results on the $R \& D$ capital stock estimates are quite a few, but not much about the regional R\&D capital stock, and that the selection of parameters is not uniform. Based on the above analysis, this paper calculates the R\&D capital stock of 30 provinces and autonomous regions (excluding Tibet) in inland 2003-2013 on the basis of the reasonable selection of parameters.

\section{DETERMINATION OF PARAMETER}

The international is widely used on the perpetual inventory method to calculate capital stock, refer to the practices of the Griliches (1980) ${ }^{[4]}$ and Goto and Suzuki(1989) $)^{[5]}$, on China's 2003-2013 provincial R\&D estimation by using the following methods:

$$
K S_{t}=(1-\delta) K S_{t-1}+I_{t-\xi}
$$

Formula, $K S_{t}$ and $K S_{t-1}$ were 1 phase and 2 phase of the R\&D capital stock, $I$

for the same price as the R\&D capital expenditure, $\xi$ for the average lag period, $\delta$ for capital stock of the constant depreciation rate.

At present, there is no uniform standard on the lag period, which is commonly used in the theory of our country, the lag period is set to 1 years, then (1):

$$
K S_{t}=(1-\delta) K S_{t-1}+I_{t-1}
$$

According to (2) calculation of the capital stock is the key to scientific reasonably determine the values of the parameters, including the current $\mathrm{R} \& \mathrm{D}$ expenditures by R\&D expenditures, data can be obtained by the China Statistical Yearbook on science and technology to check, the major concern of the other three variables: $R \& D$ expenditure price index, the same depreciation rate and the base period capital stock.

With regard to the determination of the R\&D expenditure price index, scholars from different countries have carried out different attempts. For example Jaffe (1972), such as the R\&D expenditure Price Index said for the non-financial companies wage price index and real GNP price of weighted average, which the former weight given to 0.49 , which confers on $0.51^{[6]}$; Loeb and Lin to R\&D personal wage price index and the equipment investment of the GNP price index weighted average value to represent, the former giving weight of 0.55 , whoch gives weight of 0.45 .Domestic scholars on the R\&D expenditure price index mainly adopts two methods. A is using weighted average of the consumer price index and fixed assets investment price index, more representative is Pingfang Zhu and Xu Weimin ${ }^{[7]}, \mathrm{Li}$ Xiaodong, Liu Jiancui ${ }^{[8-9]}$ also used this method; another is uses industrial product factory price index and GDP implied price index of the weighted average, each assigned 0.5 weight, more representative stone Kui ran, Zhao Shunlong, Xiaosheng $\mathrm{Li}^{[10,2] \mathrm{a}}$ nd so on .

For the provincial R\&D expenditure price index, the Chinese scholars mainly adopt GDP reduction index to 
reduce, for example, Xiao Min, Xie Fu Ji, Wang Meng Xin ${ }^{[11-12]}$. In this paper, we use the Li Xiaosheng ${ }^{[2]}$ approach, the $\mathrm{R} \& \mathrm{D}$ expenditure price index of each region is expressed as the weighted average value of the factory price index of industrial products and the implicit price index of GDP, each with a weight of 0.5 .

\section{DEPRECIATION RATE}

R\&D capital is different from the fixed capital, the depreciation of the capital mainly refers to the renewal of knowledge. Through the point of view of literature, due to the lack of relevant data, China R\&D capital depreciation rate mostly uses the empirical method of setting, such as Xiao Sheng Li (2007) ${ }^{[2]}$ consider China is a developing country, the renewal of knowledge not in developed countries, with $12 \%$ of the depreciation rate, WangKang $(2011)^{[13]}$ also uses this data. Tritors $(2013)^{[3]}$ and so on considering the R\&D capital depreciation rate is larger than that of material capital, depreciation of basic research in our country rate set to $10 \%$, applied research and experimental development and depreciation rate is set for 15\%;Peng Jian Ping and Li Yongcang (2014) ${ }^{[14]}$ respectively by $10 \%, 15 \%$ and $20 \%$ of the depreciation rate of $R \& D$ capital stock estimates; Shi Kui and Zhao Shunlong ${ }^{[10]}(2010)$ by $15 \%$ depreciation rate.

On China's provincial R\&D capital stock depreciation rate, Meng Xin Wang ${ }^{[12]} 18 \%, 15 \%$ and $12 \%$ are applied for the eastern, central and western region; in order without loss of generality, here we use Xiao Min (2009) ${ }^{[11]}$, and other practices, with $15 \%$ of the depreciation rate.

The base amount of capital

According toGoto and Suzuki (1989) approach, it is assu med that the average growth rate of the R\&D capital stock is equal to the average growth of R\&D capital expenditures,

$$
\left(K S_{t}-K S_{t-1}\right) / K S_{t-1}=\left(I_{t}-I_{t-1}\right) / I_{t-1}=g \quad \text { (average }
$$
growth of $\mathrm{KS})$, this can be obtained, when $\mathrm{t}=1$, $K S_{1}=(1+g) K S_{0} \quad, \quad$ by (2) can be obtained $K S_{1}=I_{0}+\delta K S_{0}$, two type available computational formula of basic base stock:

$$
K S_{0}=I_{0} /(g+\delta)
$$

\section{RESULTS ANALYSIS}

According to the above parameters, the formula (1) to 2003 for changeless price of China's 30 provinces 2003-2013 R\&D capital stock estimates results as shown in "Table I" below.

\begin{tabular}{|c|c|c|c|c|c|c|c|c|c|c|c|c|}
\hline region & 2003 & 2004 & 2005 & 2006 & 2007 & 2008 & 2009 & 2010 & 2011 & 2012 & 2013 & average \\
\hline Beijing & 922.11 & 1040.0 & 1188.3 & 1368.0 & 1562.1 & 1780.5 & 1990.2 & 2288.8 & 2638.5 & 3012.0 & 3429.0 & 1929.05 \\
\hline Tianjin & 109.54 & 133.54 & 165.11 & 206.84 & 262.85 & 326.52 & 408.27 & 505.70 & 614.85 & 764.19 & 945.72 & 403.92 \\
\hline Hebei & 121.42 & 141.26 & 159.92 & 187.29 & 225.38 & 264.81 & 304.43 & 363.99 & 418.84 & 491.82 & 589.42 & 297.14 \\
\hline Shaanxi & 47.47 & 56.17 & 68.54 & 79.96 & 97.36 & 120.02 & 142.33 & 176.67 & 203.70 & 239.25 & 283.67 & 137.74 \\
\hline Neimeng & 15.74 & 19.77 & 24.20 & 31.20 & 40.78 & 54.15 & 70.30 & 98.15 & 125.35 & 161.85 & 203.66 & 76.83 \\
\hline Liaoning & 297.81 & 336.11 & 389.67 & 445.43 & 499.48 & 565.61 & 628.80 & 722.84 & 824.49 & 959.05 & 1090.0 & 614.48 \\
\hline Jilin & 105.83 & 117.76 & 133.99 & 150.01 & 164.29 & 183.38 & 199.20 & 237.44 & 260.85 & 288.64 & 327.77 & 197.19 \\
\hline Heilongjiang & 124.72 & 138.69 & 150.33 & 168.37 & 187.87 & 209.59 & 237.67 & 285.72 & 325.75 & 356.91 & 394.47 & 234.55 \\
\hline Shanghai & 410.11 & 477.51 & 569.48 & 678.56 & 815.16 & 970.77 & 1138.7 & 1355.5 & 1574.6 & 1853.9 & 2173.3 & 1092.52 \\
\hline Jiangsu & 430.64 & 516.51 & 641.34 & 787.16 & 974.55 & 1195.6 & 1487.9 & 1851.4 & 2224.7 & 2672.6 & 3229.7 & 1455.65 \\
\hline Zhejiang & 206.24 & 250.53 & 323.09 & 426.91 & 564.78 & 726.01 & 906.13 & 1116.4 & 1341.9 & 1598.4 & 1921.0 & 852.85 \\
\hline Anhui & 91.77 & 110.43 & 129.11 & 151.54 & 181.67 & 215.65 & 261.27 & 333.63 & 403.83 & 493.19 & 617.37 & 271.77 \\
\hline Fujian & 109.15 & 130.28 & 155.28 & 183.49 & 220.30 & 263.11 & 314.86 & 390.97 & 478.37 & 590.22 & 726.73 & 323.89 \\
\hline Jiangxi & 55.56 & 64.21 & 74.28 & 87.68 & 104.69 & 125.62 & 151.39 & 185.15 & 213.70 & 239.76 & 273.46 & 143.23 \\
\hline Shandong & 286.01 & 346.96 & 427.63 & 537.16 & 658.58 & 820.97 & 1034.1 & 1299.0 & 1603.6 & 1981.1 & 2435.3 & 1039.13 \\
\hline Henan & 100.01 & 119.20 & 139.87 & 166.06 & 206.71 & 254.39 & 303.06 & 386.64 & 470.01 & 572.78 & 691.26 & 310.00 \\
\hline Hubei & 171.64 & 200.71 & 223.98 & 258.03 & 302.05 & 349.27 & 413.08 & 520.55 & 632.84 & 762.86 & 913.25 & 431.66 \\
\hline Hunan & 87.32 & 104.31 & 122.96 & 143.66 & 167.35 & 200.59 & 252.97 & 331.03 & 408.29 & 498.67 & 610.58 & 266.16 \\
\hline Guangdong & 531.95 & 632.00 & 742.84 & 861.16 & 1020.1 & 1229.5 & 1478.1 & 1837.2 & 2239.1 & 2763.7 & 3373.7 & 1519.02 \\
\hline Guangxi & 34.05 & 40.18 & 45.01 & 51.14 & 58.43 & 66.81 & 80.49 & 104.20 & 130.50 & 162.24 & 200.18 & 88.48 \\
\hline Hainan & 3.23 & 3.96 & 5.41 & 6.16 & 7.24 & 8.59 & 10.24 & 14.06 & 17.72 & 23.26 & 30.36 & 11.84 \\
\hline Chongqing & 48.74 & 58.87 & 72.66 & 91.51 & 111.69 & 136.70 & 166.16 & 209.41 & 257.85 & 319.46 & 396.25 & 169.94 \\
\hline Sichuan & 289.88 & 325.82 & 350.70 & 386.40 & 424.25 & 478.35 & 531.72 & 624.06 & 724.52 & 825.71 & 952.89 & 537.67 \\
\hline Guizhou & 28.44 & 32.06 & 35.38 & 39.71 & 45.89 & 49.83 & 55.71 & 66.60 & 76.40 & 88.69 & 101.77 & 56.41 \\
\hline Yunnan & 35.52 & 41.20 & 46.54 & 58.48 & 67.59 & 78.29 & 89.92 & 106.28 & 122.33 & 143.62 & 170.54 & 87.30 \\
\hline Shanxi & 265.77 & 293.89 & 327.11 & 355.71 & 381.03 & 414.81 & 450.99 & 517.23 & 575.11 & 639.50 & 714.49 & 448.69 \\
\hline Gansu & 48.28 & 53.81 & 58.68 & 66.49 & 75.36 & 83.18 & 93.10 & 107.12 & 118.36 & 130.25 & 148.31 & 89.36 \\
\hline Qinghai & 8.81 & 9.89 & 11.20 & 12.06 & 12.87 & 13.79 & 14.38 & 17.74 & 21.32 & 25.87 & 30.17 & 16.19 \\
\hline Ningxia & 7.67 & 8.90 & 10.36 & 11.58 & 13.98 & 17.62 & 20.03 & 24.21 & 27.23 & 31.87 & 37.60 & 19.19 \\
\hline Xinjiang & 11.41 & 13.49 & 16.90 & 19.54 & 22.84 & 26.41 & 32.39 & 42.72 & 51.26 & 60.51 & 72.11 & 33.60 \\
\hline Averag & 166.89 & 193.94 & 226.99 & 267.24 & 315.91 & 374.35 & 442.26 & 537.35 & 637.53 & 758.40 & 902.80 & 438.52 \\
\hline
\end{tabular}

TABLE I. R\&D CAPITAL Stock AND AVERAGE 0F PROVINCES IN CHINA 
From a single area, China's R\&D capital stock during the study showed a steady growth trend, but at the same time there are regional development is not balanced, the phenomenon of serious polarization, as shown in "Fig. 1".

Inspection during R\&D capital stock for Beijing, the mean to 1929.05 billion yuan, the highest. The average value of minimum to Hainan, the mean only 1.184 billion yuan, Beijing 1/160, two disparity. This is mainly because Beijing is China's political and economic center, geographical adventages, the major colleges and Universities and scientific research institutes gathered, R\&D investment each year ranked first, strong research and innovation capicity and competitiveness. Hainan total staff is low, R\&D personal less, also level of Industrial Enterprises above Designated Size of Government R\&D Investment are in sufficient, leading R\&D capital stock has been living in the bottom. The top eight are Beijing, Guangdong, Jiangsu, Shanghai, Shandong, Zhejiang, Liaoning, Sichuan, the total amount of its R\&D capital stock accounted for $68.7 \%$ of the total amount of R\&D capital stock; After eight ranked respectively, Guangxi, Yunnan, Inner Mongolia, Guizhou, Xinjiang, Ningxia, Qinghai, Hainan, the R\&D the total amount of capital stock accounted for only $2.96 \%$ national $R \& D$ the total amount of capital stock, visible in China $R \& D$ capital stock has strong concentration, which also studies with a consistent results. In addition, the average value from the study period, the top eight regions in the Middle East region accounted for $75 \%$, the western and northeast regions accounted for only $12.5 \%$; In eight place after, in addition to the eastern region of Hainan Province, the rest belong to the western region. This shows that the main $R \& D$ investment in China is concentrated in the eastern region, while the western region is relatively the least $R \& D$ investment.

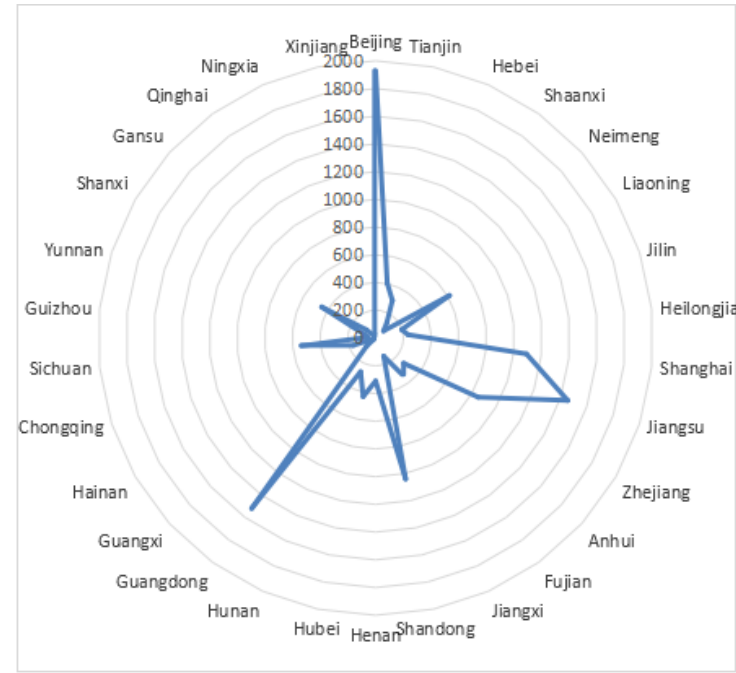

Fig. 1. R\&D capital stock and average of Provinces in China from 2003 to 2013.

From an economic point of view, during the study period, the average R\&D capital stock also presents a "East High West low" situation, as shown in table 2. In the whole period, the average value of $R \& D$ capital stock in the eastern region is the highest, the northeast region is the second, and the western region is the lowest. In 2003-2005 years, the eastern region and northeast $\mathrm{R} \& \mathrm{D}$ capital stock than the national level, the central region and the western region is lower than the national level.

TABLE II. AVERAGE R\&D CAPITAL STOCK OF EACH ECONOMIC REGION IN CHINA

\begin{tabular}{|c|c|c|c|c|c|c|c|c|c|c|c|}
\hline \multirow{2}{*}{ Region } & \multicolumn{11}{|c|}{ Year } \\
\hline & 2003 & 2004 & 2005 & 2006 & 2007 & 2008 & 2009 & 2010 & 2011 & 2012 & 2013 \\
\hline The eastern & 313.04 & 367.26 & 437.84 & 524.27 & 631.11 & 758.64 & 907.29 & 1102.3 & 1315.2 & 1575.1 & 1885.4 \\
\hline The northeast & 176.12 & 197.52 & 224.66 & 254.60 & 283.88 & 319.53 & 355.22 & 415.33 & 470.36 & 534.87 & 604.07 \\
\hline The central & 92.29 & 109.17 & 126.46 & 147.82 & 176.64 & 210.92 & 254.02 & 322.28 & 388.73 & 467.75 & 564.93 \\
\hline The western & 72.21 & 81.63 & 90.79 & 102.17 & 114.06 & 129.09 & 145.93 & 174.34 & 202.75 & 235.42 & 275.27 \\
\hline China & 163.42 & 188.90 & 219.94 & 257.22 & 301.42 & 354.55 & 415.62 & 503.56 & 594.26 & 703.29 & 832.42 \\
\hline Coefficient of variation & 0.837 & 0.847 & 0.850 & 0.855 & 0.861 & 0.864 & 0.869 & 0.880 & 0.879 & 0.8780 & 0.8784 \\
\hline
\end{tabular}

From the dynamic growth point of view, during the study period R\&D capital stocks are in the growth trend, as shown in table 3 , The national average growth rate was $18.75 \%$, of which 13 regions of Inner Mongolia, Hainan, Zhejiang, Tianjin, Shandong, Chongqing, Jiangsu, Hunan, Henan, Anhui, Xinjiang, Guangdong, Shanxi, higher than the national average, and in addition to Shanxi Province the remaining 12, annual growth rate of more than 20\%; after seven, respectively, Shanxi, Gansu, Jilin, Heilongjiang, Sichuan, Qinghai, and Liaoning. More obvious features including Beijing, Sichuan, Inner Mongolia, and Hainan, which Beijing, Sichuan R\&D capital stock are located in the first and eighth position, however, the growth rate is far lower than the national average growth rate, indicating that the capital stock accumulated to a certain extent after growth started to slow down. Inner Mongolia and Hainan R\&D capital stock are located in the sixth in the countdown and b. FROM 2003 TO 2013 (UNITS: ONE HUNDRED MILLION YUAN) the last one, but its growth rate it occupies the top two, the momentum of rapid development, the visible local governments and enterprises to strengthen the importance of research and development, continue to increase investment, the consciousness and ability of innovation continued to increase. From the regional economic growth rate, the eastern region average of more than $20 \%$, suggesting that eastern area not only soild foundation, a good momentum of development; and northeast area development rate is only $12.7 \%$, far below the national level, if the Northeast do not adjust or increase investment, it is bound to is the central region (the average growth rate of $19.85 \%$ ) to catch up; And the western region the average growth rate of only $17.15 \%$, lower than the national level, suggesting that the western region under the weak foundation, development potential is still insufficient, the state if not intensify efforts to tilt, the gap with East Midlands will widening. 
TABLE III. AVERAge AnNual Growth Rate of R\&D CAPITAL Stock of Provinces In China

\begin{tabular}{|c|l|l|l|l|l|}
\hline Region & $\begin{array}{c}\text { Average annual } \\
\text { growth rate }\end{array}$ & \multicolumn{1}{|c|}{ Region } & $\begin{array}{c}\text { Average annual } \\
\text { growth rate }\end{array}$ & $\begin{array}{c}\text { Average annual } \\
\text { growth rate }\end{array}$ \\
\hline Beijing & $14.04 \%$ & Zhejiang & $25.09 \%$ & Hainan & $25.37 \%$ \\
\hline Tianjin & $24.07 \%$ & Anhui & $21.04 \%$ & Chongqing & $23.32 \%$ \\
\hline Hebei & $17.14 \%$ & Fujian & $20.89 \%$ & Sichuan & $12.68 \%$ \\
\hline Shaanxi & $19.61 \%$ & Jiangxi & $17.32 \%$ & Guizhou & $13.64 \%$ \\
\hline Neimenggu & $29.25 \%$ & Shandong & $23.89 \%$ & Yunnan & $17.03 \%$ \\
\hline Liaoning & $13.86 \%$ & Henan & $21.36 \%$ & Shanxi & $10.41 \%$ \\
\hline Jilin & $12.00 \%$ & Hubei & $18.25 \%$ & Gansu & $11.89 \%$ \\
\hline Heilongjiang & $12.24 \%$ & Hunan & $21.54 \%$ & Qinghai & $13.29 \%$ \\
\hline Shanghai & $18.15 \%$ & Guangdong & $20.31 \%$ & Ningxia & $17.30 \%$ \\
\hline Jiangsu & $22.34 \%$ & Guangxi & $19.51 \%$ & Xinjiang & $20.34 \%$ \\
\hline The eastern & $21.13 \%$ & The central & $19.85 \%$ & The northeast & $12.70 \%$ \\
\hline The western & $17.15 \%$ & China & $18.57 \%$ & & \\
\hline
\end{tabular}

\section{CONCLUSION AND ENLIGHTENMENT}

The perpetual inventory method, in 2003 prices for the same price, of China's 30 provinces, autonomous regions and municipalities 2003-2013 R\&D capital stock was calculated, and the analysis and comparison of the regional differences of R\&D capital stock, which could provide data support for the related research. The main conclusions and implications are as follows:

2003-2013 during R\&D capital stock in China's 30 provinces, municipalities and autonomous regions showed a growth trend, this is mainly because in our country in recent years, more attention to technological innovation and scientific and technological progress, increasing the investment on R\&D and the accumulation was growing. But at the same time, the $R \& D$ capital stock in all regions of the development is unbalanced, serious polarization, strong concentration, the eastern part of the northeast and the Midwest decline and so on. This is due to the eastern coastal areas have a higher level of economic development, there is relatively strong scientific research ability of aggregation, with strong R\&D base, government and corporate R\&D investment have been living in high; and the central and western region's economy is relatively backward, do not have the location advantage, development foundation relatively weak into insufficient. From the growth rate of view, the eastern region is still far ahead, the lack of stamina in the northeast region, the central region on catch up with the trend is obvious, the western region behind the recent situation is difficult to change.

\section{REFERENCE}

[1] Lu Zhiguo. R\&D investment role in the transmission mechanism of technology innovation analysis[J]. Shenzhen University Journal(HUMANITIES AND SOCIAL SCIENCES EDITION), 2005,22(5):25-28

[2] $\mathrm{Li}$ Xiaosheng. Estimation of China's R\&D capital stock and economic growth [J] China Statistics, 2007 (11):40-41

[3] Li Shumei, song song, Fan Pengxiang, Zhu Rongjun. Estimation of R \&D capital stock in China [J]. SAR economy, 2013 (6): 173-175

[4] GRILICHES Z. R\&D and Productivity Slowdown [J] .American Economic Review, 1980 (70):343-348.

[5] Goto Akira, Suzuki Kazuyuki. R\&D Capital, rate of Return on R\&D Investment and Spillovers of $R \& D$ in Japanese Manufacturing
Industries [J]. Review of Economics and Statis 564.

[6] Jaffe S.A price index for deflation of academic R\&D expenditure $[R]$. Washington D C: The National science Foundatian, 1972.

[7] Zhu Pingfang, Xu Weimin. The influence of government's science an $\mathrm{d}$ technology incentive policy on $\mathrm{R} \&$ investment and patent output of large and medium sized industrial enterprises An Empirical Study of Shanghai city [J]. economic research, 2003 (6 ): $45-53$.

[8] Li Xiangdong, Li Nan, Bai Junhong, Xie Zhongqiu et al. Research an $\mathrm{d}$ innovation efficiency of high tech industry [J]. China soft science, 2 011 (2): 52-61.

[9] Liu Jiancui, Zheng Shilin, Wang Yanan. China R\&D (R\&D) capital s tock estimation: 1978 -

2012[J]. economics and management research, 2015, 2 (2): 18-25.

[10] Shi Kui ran, Zhao Shunlong.R\&D capital stock in our country and so me indicators of high technology industry correlation analysis [J]. Sci ence science and management of science and technology, 2010 (01): 107-111.

[11] Xiao Min, Xie Fu Ji. Spatial distribution characteristics of R\&D capit al stock in China [J]. science and technology management research, 2 009 (8): 435-439.

[12] Wang Mengxin. Measurement of regional R\&D capital stock in Chin a [J]. Journal of Jiangsu University (SOCIAL SCIENCE EDITION), 2011, 13 (1): 84-88.

[13] Wang Kang. Estimation of R\&D capital stock in China [J]. Journal of Wuxi Institute of Commerce, 2011, 11 (4): 12-14.

[14] Li Yongcang, Peng Jianping.FDI stock and independent innovation b ased on the empirical study of inter provincial dynamic panel [J]. esti mation GMM economic latitude and longitude, 2014,31 (1): 79-83. 